\title{
Tools and Activities for developing Higher Order and Professional Skills with a case study on the subject of Computer Architecture and Organization
}

\author{
M. Somasundaram ${ }^{1}$, P. Latha ${ }^{2}$ \\ ${ }^{1,2}$ Department of Electronics and Communication Engineering, R.M.K. Engineering College, RSM Nagar, Kavaraipettai, \\ Thiruvallur District, Tamilnadu - 601206, India \\ ${ }^{1}$ mss.ece@rmkec.ac.in \\ ${ }^{2}$ pla.ece@rmkec.ac.in
}

\begin{abstract}
Higher-order thinking, commonly known as higher order thinking skills (HOTS), is a concept of education reform based on the learning taxonomies such as Bloom's taxonomy. For various Bloom's Taxonomy levels as Remembering, Understanding, Applying, Analysing, Evaluating and Creating, digital tools are available for students to develop those levels of skills. However, it requires that for each subject area in the engineering education, the faculty members have to identify the specific thinking skills as applicable for the subject and need of the student. Then they have to design the activities and projects with the necessary specific tools.
\end{abstract}

In view of the above, a group of faculty members in our institution took up a case study on Computer Architecture and Organization and identified the thinking skills to be developed. Based on this, they designed a set of activities and projects with the necessary tools as specific to the subject. It is required to use the generic digital tools.

Keywords: Higher order thinking skills (HOTS), Bloom's Taxonomy, Tools and activities

\section{Introduction}

Higher-order thinking, known as higher order thinking skills (HOTS), is a concept of education reform based on learning taxonomies (such as Bloom's taxonomy). The idea is that some types of learning require more cognitive processing than others, but also have more generalized benefits. [1]

Bloom's Digital Taxonomy outlines critical thinking skills with the levels as

- Remembering

- Understanding

- Applying

- Analysing

- Evaluating

- Creating

So, the learning requires a series of specific tasks for the students (learners) to develop the thinking at various levels as mentioned above. Tools can enable students to develop higher order thinking skills in the subjects they learn.

\section{Tools for the Higher Order Thinking:}

Following are some of the digital tools available for the various levels of higher order thinking. [1]

Tools for Understanding: Mind mapping is one of the best activities for understanding, especially to create collaboration among learners. [2] Tools like Mind maple [3] and Mind Node [4] can be used for mind mapping. Students can also get answers to their questions by making use of simple tools like forums, or by conducting interviews using video tools like Skype, Zoom, or other such video conferencing tools.

Tools for Applying: Website/blogging tools like Weebly [5] and Edublogs [6] are the resources for applying the concepts understood. For task management and internal communication kind of processes, tools like Basecamp [7] and Asana [8] can be used. These tools can be used by students for internal communication and to discuss the application of the concepts.

Tools for Analysing: Students can try out tools like Lucid chart [9] and Creately [10] for data visualization and graph making. Such tools can be used by students to analyse the concepts learnt using various structuring diagrams, graphical representation and to discuss among themselves.

Tools for Evaluating: The key difference between Analysing and Evaluating is collaboration. It could be useful to display the product out there for critique and beta testing. For evaluating information, tools like Snopes [11] and FactCheck.org [12] can be used. Students should practice positive commenting and constructive feedback on social media posts, video feeds, and generally for an online interaction.

Tools for Creating: This is the highest form of Bloom's Taxonomy, and HOTS (higher-order thinking skills). Students can build digital portfolios using Google Sites, Evernote [13], and VoiceThread [14]. Such tools can create documents and notes about the subject using text, images, audio, PDFs, etc.

\section{Need for Tools specific to the subject}


For the various Bloom's Taxonomy levels as Remembering, Understanding, Applying, Analysing, Evaluating and Creating, digital tools are available as given above for students to develop those levels of skills.

However, the above tools are generic and applicable to all subjects. The levels of higher order thinking will be achieved only based on the student's in-depth knowledge and the level of deep discussions they have at analysing or evaluating levels. The levels achieved may also vary from student to student.

So, it is important that for each subject area in the engineering education, the faculty members have to identify the specific thinking skills as applicable for the subject and requirement of students. Then they have to design the activities and projects with the necessary specific tools. Only by designing such activities and also providing the necessary tools, students will be able to implement the activities and achieve well defined outcomes of Understanding, Applying, Analysing, Evaluating and Creating.

\section{Case study in a specific subject}

In view of the above, a group of faculty members in our institution took up a case study of the subject of Computer Architecture and Organization (CAO). The subject is being offered as a part of the curriculum of Undergraduate Program i.e. Bachelors of Engineering (B.E) in Electronics and Communication Engineering (ECE). [15] The institution, R.M.K. Engineering College in Tamil Nadu, India, an autonomous institution, affiliated to Anna University. This subject has the Course Objectives as follows:

- To make students understand the basic structure and operation of digital computer

- To familiarize with implementation of fixed point and floating-point arithmetic operations

- To study the design of data path unit and control unit for processor

- To understand the concept of various memories and interfacing

- To introduce the parallel processing technique

In the curriculum and syllabus, MIPS architecture has been used throughout to learn the concepts. MIPS (Microprocessor without Interlocked Pipelined Stages) is a reduced instruction set computer (RISC) instruction set architecture (ISA) developed by MIPS Computer Systems, now MIPS Technologies, based in the United States.

The faculty members identified the thinking skills to be developed. Based on this, they designed a set of activities and projects with the necessary tools as specific to the activities for the subject. In addition, it was also required to use the generic digital tools.
A summary of the skills required and activities are summarized in the table as below:

\begin{tabular}{|c|l|l|l|}
\hline No & \multicolumn{1}{|c|}{$\begin{array}{c}\text { Skill Levels } \\
\text { required }\end{array}$} & \multicolumn{1}{|c|}{$\begin{array}{c}\text { CAO Subject } \\
\text { specific Skills } \\
\text { required }\end{array}$} & \multicolumn{1}{|c|}{ Activities } \\
\hline 1 & Understanding & $\begin{array}{l}\text { Instruction Set } \\
\text { Architecture }\end{array}$ & Mind Map \\
\hline 2 & Applying & $\begin{array}{l}\text { Terminologies } \\
\text { Assembly level } \\
\text { applied to some } \\
\text { functions }\end{array}$ & Visual Quiz \\
\hline 3 & Analysing & $\begin{array}{l}\text { Functioning of } \\
\text { computer } \\
\text { architecture }\end{array}$ & $\begin{array}{l}\text { Simulation of } \\
\text { program execution }\end{array}$ \\
\hline 4 & Evaluating & $\begin{array}{l}\text { Effective usage of } \\
\text { computer } \\
\text { architecture }\end{array}$ & $\begin{array}{l}\text { Comparing of } \\
\text { different programs } \\
\text { of same functions }\end{array}$ \\
\hline 5 & $\begin{array}{l}\text { Creating } \\
\text { Professional Skills }\end{array}$ & $\begin{array}{l}\text { Developing } \\
\text { applications }\end{array}$ & $\begin{array}{l}\text { Developing } \\
\text { software } \\
\text { application to } \\
\text { demonstrate the } \\
\text { computer } \\
\text { architecture }\end{array}$ \\
\hline & & $\begin{array}{l}\text { Programs to be } \\
\text { used by others }\end{array}$ \\
\hline
\end{tabular}

Table 1: Subject specific skills required Vs Activities

\section{Activities for Understanding}

Understanding the concepts is to appreciate and recognize how all the topics are interrelated. The subject is centred around Instruction Set Architecture (ISA) of a computer.

- The activity is designed to build a Mind Map of the subject for better understanding of all topics of the subject and how they are inter-related.

It also requires that students understand all technical terminologies, the technical meanings. It will be helpful if they understand why these terminologies are defined as typically, they are analogies of real-life things or concepts, but applied to this subject.

- The activity is to conduct a quiz to students.

\section{Mind Map}

Students were given an activity on developing Mind Map in the Subject (CAO).

Following are some of the examples of Mind Maps developed by students. 


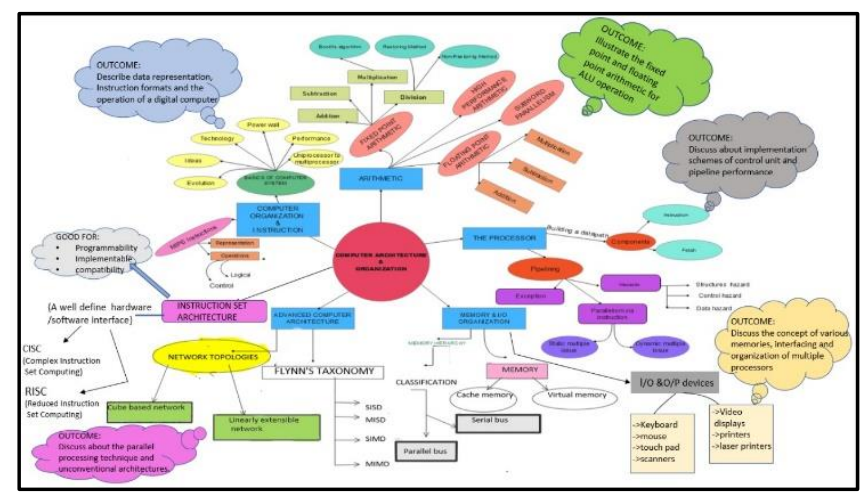

Fig 1. Sample of a Mind Map (for representation only)

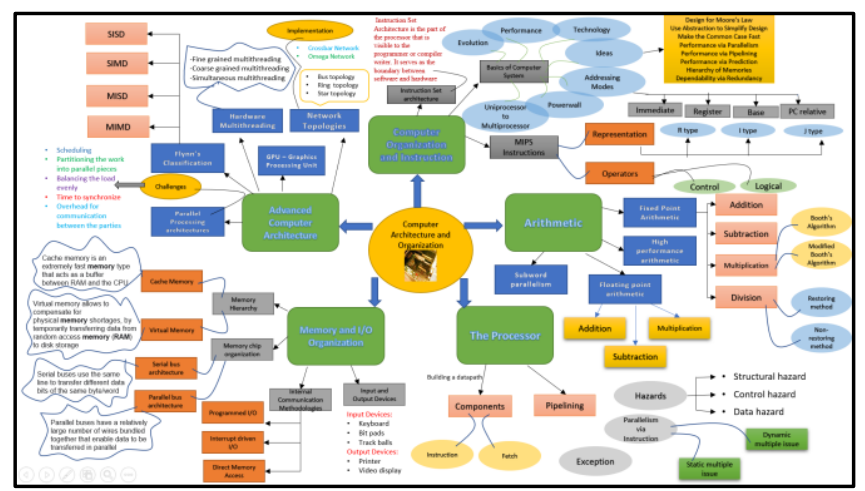

Fig 2. Sample of a Mind Map (for representation only)

The exercise of the above by the students was useful for them to get better understanding of the subject. Following are some of the feedback given by the students who developed the Mind Maps for the subject.

- The mind map actually allows us to clearly understand all the topics present in computer architecture and organization. As mind map is the graphical representation of the contents present, it made us understand the complex things in a very easy way. We think this will be greatly helpful while preparing for the examination and it will also serve as a good tool during revision.

- We can get to know the topics present in all 5 units. On continuation, we can note the subtopics present in it. Hence, it will be helpful in the time of examination for revising the topics. We could even find some explanation related to it in simple manner

- Mind mapping clearly shows the outline of the particular subject and its simplicity allows to capture the ideas more quickly. The visual nature of a mind map normally helps to recall information in a better way and it is considered as a more engaging form of learning.

\section{Innovative Visual Quiz}

Another activity was given to students for developing an innovative quiz with a visual question showing 2 pictures and they were asked to find out the technical term in the subject. This created a lot of understanding of the various terminologies, their meanings and why the names are given so. It acted as a good learning exercise of the understanding part both for the students who designed them as well as the students who participated.

Some of the examples are:

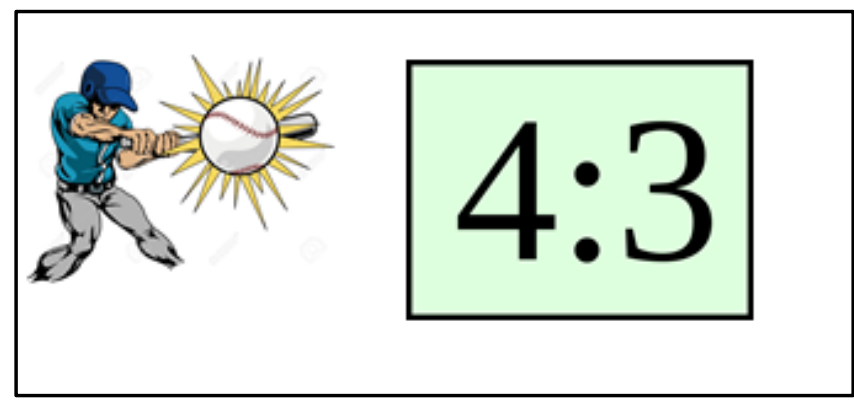

Fig 3. Visual Quiz for Hit Ratio

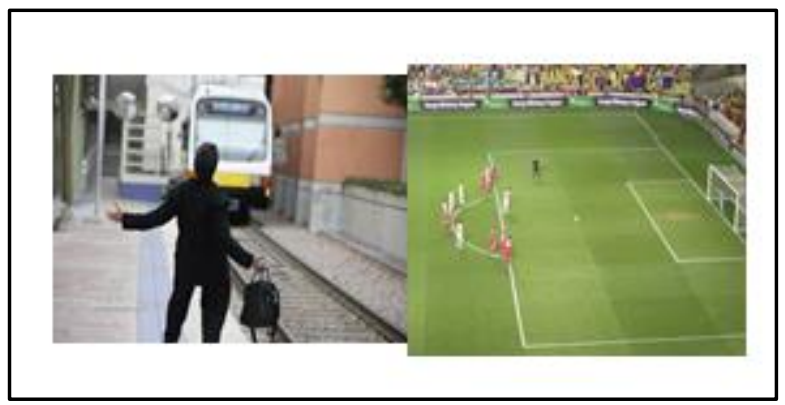

Fig 4. Visual Quiz for Miss penalty

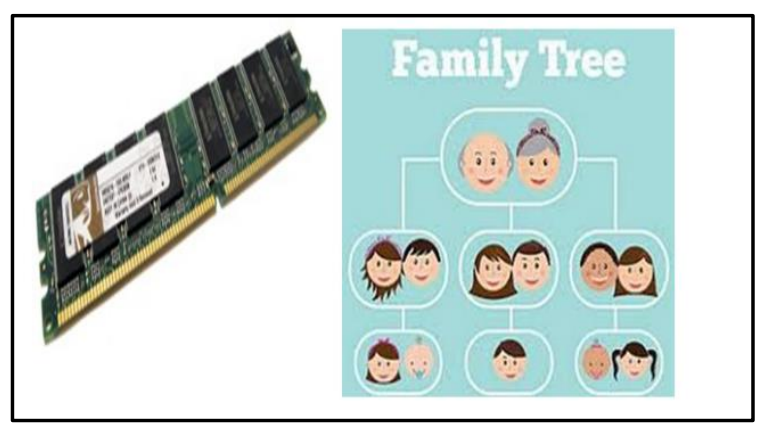

Fig 5. Visual Quiz for Memory Hierarchy

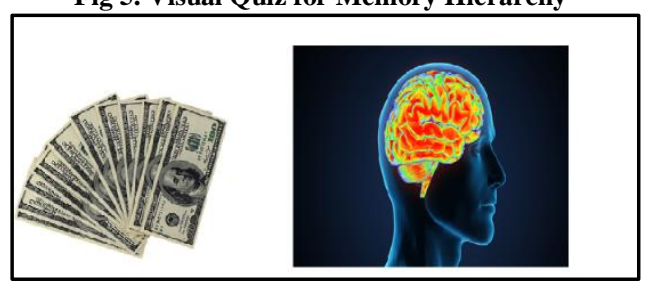

Fig 6. Visual Quiz for Cache Memory

- $\quad$ Hit Ratio 
- Miss penalty

- Memory Hierarchy

- Cache memory

\section{Activities for Applying}

Once the students develop a good 'understanding' of the concepts of ISA, they can develop assembly level programs using the ISA. This will enable students to learn at 'applying level' of the subject.

- The activities can be developed by some computer assembly level instructions.

Activities were given for applying the concepts of computer programming at assembly level. Students were asked to write assembly level programs for specific functions.

The examples are:

- Calculate an equation $y=\left(a^{*} x^{\wedge} 2\right)+(b * x)+c$

- Calculate the Factorial for a given number

- Generate a Fibonacci sequence (Fn), of 'n' numbers such that each number is the sum of the two preceding ones, starting from 0 and 1

This activity helped the students to apply the theoretical concepts for real-life situations.

\section{Activities for Analysing}

As students learn to apply their concepts into practical implementation, they have to analyse how the practical implementation works. This necessitates to know, how the assembly level programs actually work inside the computer.

- The activity is meant to take any simulation tool and run their assembly level programs in order to see how it works inside the computers.

For this, a simulation tool called WeMips Online Mips Emulator [16] was selected. Students are asked to run the programs, they prepared in the earlier level (Applying)

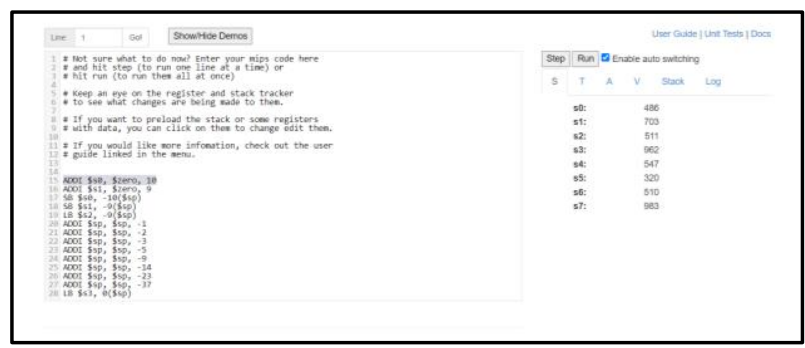

Fig 7 WeMips Online Mips Emulator (for representation only)

This tool enables the student to go step-by-step and execute the instruction. For each instruction, the simulation tool shows the status of various parts of computer like accumulator, registers, memory, stack etc.

Students are able to analyse how their assembly level programs work inside the computer.

\section{Activities for Evaluation}

Evaluating the concepts can be evaluating and comparing different versions of the same program and their performances.

- The activities can be to develop different versions of logically same assembly level programs and comparing them.

The activity was that students were asked form teams of 3 students each. Each team was asked to do the following:

The students were asked to take the 3 examples of program given in the 'applying' level. In a team, each student developed the assembly level program for the example. Then the team conducted a joint meeting, had a review and walkthrough each program to verify the correctness. Once all 3 programs were found to be correct, each student was asked to find out the execution time taken for each program. Then they had to compare and evaluate the 3 programs on why the 3 programs although functionally same, had different execution times.

The examples are:

- Calculate an equation $\mathrm{y}=\left(\mathrm{a}^{*} \mathrm{x}^{\wedge} 2\right)+\left(\mathrm{b}^{*} \mathrm{x}\right)+\mathrm{c}$

- Calculate the Factorial for a given number

- Generate a Fibonacci sequence (Fn), of ' $n$ ' numbers such that each number is the sum of the two preceding ones, starting from 0 and 1

Such evaluation level of thinking and discussions brought out the different ways of implementation of same function and the effective usage if instructions and registers.

\section{Activities for Creating}

Creating can be developed based on some demonstrations of how the assembly level languages will work.

- The activities and mini-project can be developed according to the dynamic and animated graphics of how the computer architecture operates the data and control paths for the sample assembly level programs as developed above.

- Another activity can actually use the programs developed by users other than the students who developed it initially.

Creating a Software Application to demonstrate the working of Computer Architecture 
Students were asked to develop a software application in a higher-level language like $\mathrm{C}$ or $\mathrm{C}++$ or Java to implement the above function. The development of the software application brought out all aspects of challenges and thinking in Creating Level such as requirements analysis, design, user interface design, performance and in-depth understanding of the computer architecture.

\section{Using the programs by users}

Students were asked to use and test the assembly level programs of other students. This brought out various issues like usability, handling error conditions, user-friendly interfaces required etc. So, the developers of the programs developed thinking skills on creating level on how to design and create programs not just for learning, but for its maximum usage by others.

\section{Students Feedback}

The above activities were done by teams of students. Then the students presented them to a class of 64 students to get their feedback. The summary of the feedback is as follows:

\begin{tabular}{|l|c|}
\hline $\begin{array}{l}\text { Bloom's taxonomy will help me to develop } \\
\text { more knowledge and thinking on any subject }\end{array}$ & $79.69 \%$ \\
\hline $\begin{array}{l}\text { It will help if I do the HOTS activities as } \\
\text { presented to develop knowledge on CAO }\end{array}$ & $82.81 \%$ \\
\hline $\begin{array}{l}\text { Doing activities will improve my level of } \\
\text { thinking in the subject }\end{array}$ & $89.06 \%$ \\
\hline $\begin{array}{l}\text { Developing higher-level thinking will help } \\
\text { in doing projects for competitions, research } \\
\text { projects, etc }\end{array}$ & $92.19 \%$ \\
\hline $\begin{array}{l}\text { I will be interested in doing such activities in } \\
\text { some subjects in the future. }\end{array}$ & $89.06 \%$ \\
\hline
\end{tabular}

\section{Conclusions}

The above activities have created different levels of higher order thinking skills and professional skills among the students. It also demonstrated that each subject has to be taken up separately. The thinking areas have to be designed in specific to the subject and the activities have to be planned based on the specific thinking areas as required for the subject.

\section{Acknowledgement}

The authors wish to thank the students who actively participated in the activities and shared their feedback and inputs to this paper. The authors wish to thank the students Yaswini, Geetha and Jayasoundarya who prepared the Mind Maps and Assembly level programs and also for conducting evaluation of the programs at various thinking levels. The authors wish to thank the students Jagadeeswari, Keerthana and Spoorthi who prepared and conducted the innovative visual quiz program.

\section{Corresponding Author}

M.Somasundaram, Department of Electronics and Communication Engineering, R.M.K. Engineering College, RSM Nagar, Kavraipettai, Thiruvallur District, Tamilnadu 601206, India

Email: $\underline{\text { mss.ece@rmkec.ac.in }}$

\section{References}

[1] https://wabisabilearning.com/blogs/critical-thinking/26critical-thinking-tools-blooms-taxonomy

[2] https://www.mindmapping.com/ : How to make a Mind Map with Mind Mapping software

[3] https://www.mindmaple.com/

[4] https://apps.apple.com/us/app/mindnode-mindmap/id1218718027

[5] https://www.weebly.com/in

[6] https://edublogs.org/

[7] https://basecamp.com/

[8] https://asana.com/

[9] https://www.lucidchart.com/pages/

[10] https://creately.com/

[11] https://www.snopes.com/

[12] https://www.factcheck.org/

[13] https://evernote.com/

[14] https://voicethread.com/

[15] Curriculum and syllabus for B.E. (ECE), Anna University

https://cac.annauniv.edu/PhpProject1/aidetails/afug_2017_f u/03.\%20B.E.\%20ECE\%20final.pdf

[16] WeMips Online Mips Emulator : https://rivoire.cs.sonoma.edu/cs351/wemips/ 